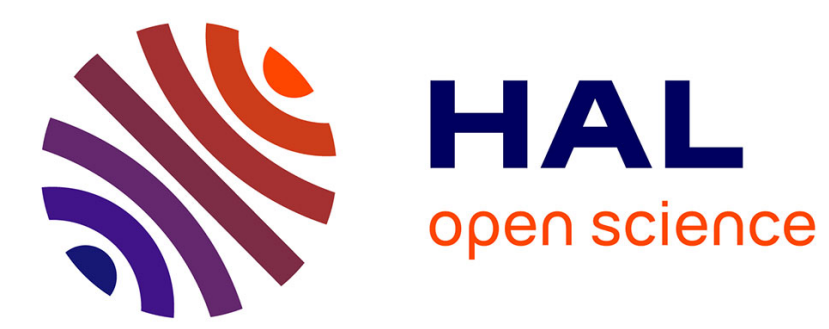

\title{
An Aging-Aware Life Cycle Cost Comparison between Supercapacitors and Li-ion Batteries to Smooth Direct Wave Energy Converter Production
}

Thibaut Kovaltchouk, Hamid Ben Ahmed, Bernard Multon, Judicael Aubry, Pascal Venet

\section{To cite this version:}

Thibaut Kovaltchouk, Hamid Ben Ahmed, Bernard Multon, Judicael Aubry, Pascal Venet. An AgingAware Life Cycle Cost Comparison between Supercapacitors and Li-ion Batteries to Smooth Direct Wave Energy Converter Production. 2015 IEEE PowerTech, Jun 2015, Eindhoven, Netherlands. pp.16, 10.1109/PTC.2015.7232248 . hal-01195523

\section{HAL Id: hal-01195523 \\ https://hal.science/hal-01195523}

Submitted on 7 Sep 2015

HAL is a multi-disciplinary open access archive for the deposit and dissemination of scientific research documents, whether they are published or not. The documents may come from teaching and research institutions in France or abroad, or from public or private research centers.
L'archive ouverte pluridisciplinaire HAL, est destinée au dépôt et à la diffusion de documents scientifiques de niveau recherche, publiés ou non, émanant des établissements d'enseignement et de recherche français ou étrangers, des laboratoires publics ou privés. 


\section{An Aging-Aware Life Cycle Cost Comparison between Supercapacitors and Li-ion Batteries to Smooth Direct Wave Energy Converter Production}

\author{
Thibaut Kovaltchouk, \\ Hamid Ben Ahmed, \\ Bernard Multon \\ SATIE CNRS UMR8029 \\ ENS Rennes \\ Bruz, France \\ thibaut.kovaltchouk@ens-rennes.fr
}

\author{
Judicaël Aubry \\ Energy and Embedded systems \\ for transportation \\ ESTACA'Lab \\ Laval, France
}

\author{
Pascal Venet \\ AMPERE UMR CNRS 5005 \\ Université Lyon 1, Université de Lyon \\ 43 bd du 11 Novembre \\ Villeurbanne, France
}

\begin{abstract}
This article compares the performance of two energy storage technologies, namely supercapacitors and Li-ion batteries, in the context of Direct Wave Energy Converters (DWEC). Both the sizing and management of an Energy Storage System (ESS) are described, and the SEAREV project has been used as an example. The main objective is to compare the two technologies on the basis of their life cycle cost. The ESS is necessary for grid integration due to the flicker constraint, which is not being satisfied without storage. The rule-based energy management approach introduced herein depends on the State of Energy of this ESS as well as the power produced by the DWEC. This management strategy has been optimized for each size in order to reduce aging speed while strictly respecting the flicker criterion. The final design is expected to minimize total system cost, i.e. the sum of investment cost and operating cost (losses and replacements). The aging models applied take into account temperature and cycling effect in order to estimate this replacement cost. Such an optimization routine is especially critical for offshore systems like Direct Wave Energy Converters, which require both cost reduction and high reliability.
\end{abstract}

Index Terms-Supercapacitors, Li-ion batteries, Electrical Energy Storage System, Life Cycle Cost, Aging, Design optimization, Life Estimation, Power Smoothing, , Direct Wave Energy Converter, Grid Integration, Energy Quality, Flicker.

\section{INTRODUCTION}

The integration to the grid is one of the keys to the development of renewable sources, as Direct Wave Energy Converters (DWEC). In particular, flicker has been identified

This work has been supported by the French National Research Agency $(A N R)$ within the project QUALIPHE (power quality and grid integration of direct wave energy converters), which is part of the PROGELEC program. (C) 2015 IEEE. Personal use of this material is permitted. Permission from IEEE must be obtained for all other uses, including reprinting/republishing this material for advertising or promotional purposes, collecting new collected works for resale or redistribution to servers or lists, or reuse of any copyrighted component of this work in other works.

Kovaltchouk, Thibaut; Ben Ahmed, Hamid; Multon, Bernard; Aubry, Judicael; Venet, Pascal, "An Aging-Aware Life Cycle Cost Comparison between Supercapacitors and Li-ion Batteries to Smooth Direct Wave Energy Converter Production,” PowerTech, 2015 IEEE Eindhoven, pp.1,6, June 29 2015-July 2 2015

DOI: 10.1109/PTC.2015.7232248 as an important element for wind turbines [1] and wave energy converters [2]-[4]. Indeed, the combination of the weak grid (because of the near-shore distribution grid) and fluctuations in production can cause significant flicker non-compliance. Smoothing the production with an Energy Storage System (ESS) is one way to solve this grid integration problem. The wave energy converter considered in this study is the SEAREV [5] (cf. Figure 1). The instantaneous produced power by a single unit is between 0 and $1.1 \mathrm{MW}$ with an average production (over a year) of $126 \mathrm{~kW}$.

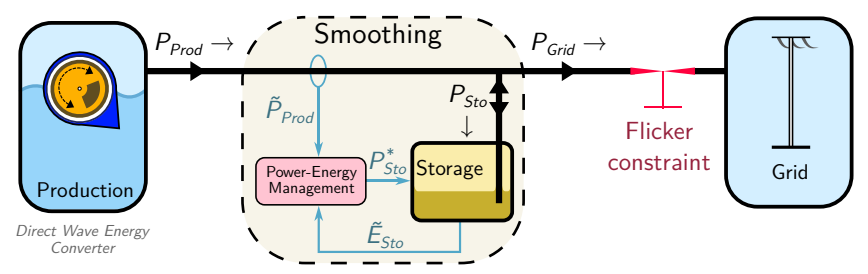

Fig. 1. Smoothing the power produced by a Wave Energy Converter thanks to an Energy Storage System for the purpose of satisfying a flicker constraint

Supercapacitors can hold a large number of cycles and offer a reduced cost per unit of power [4]. That led to consider this solution [4] [6] for the ESS. In order to reduce costs, a comparison is drawn between these devices and other technologies, more specifically the high-power Li-ion battery, which is definitely capable of competing with a supercapacitor in terms of power cycling or cost per unit of power, for examples with Lithium Titanate technology.

The purpose of this study therefore is to minimize the ESS cost while ensuring that the energy quality constraint has been satisfied (see Fig. 2). Other impacts, as for example environmental impact, like greenhouse gas emission or energy consumption, could also be compared, but are not a part of this study. Therefore, the energy management and the sizing will be optimized under a non-linear constraint on the power injected into the grid.

Past uses of a life cycle cost analysis as part of a sizing 


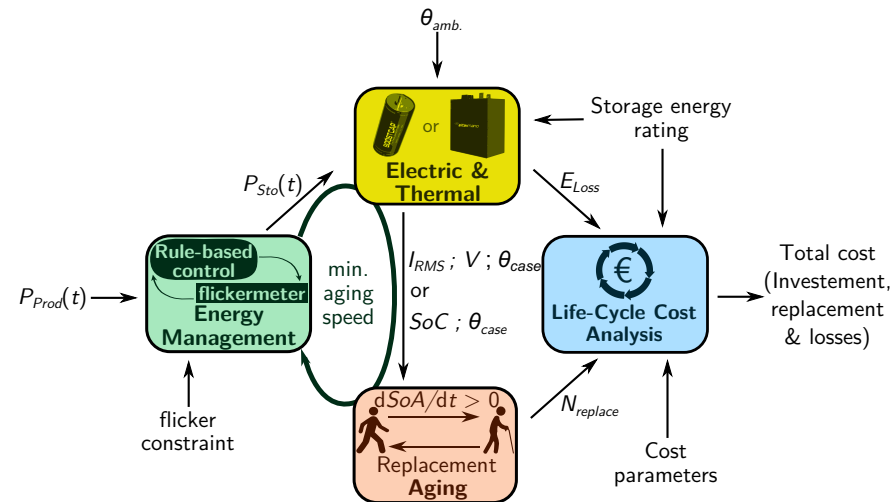

Fig. 2. Life cycle cost analysis applied to storage capacity sizing using electric, thermal and aging models with an optimized management strategy

process are limited [6]-[8]. The life cycle analysis conducted for this problem with supercapacitors under similar hypotheses has already been presented in [4]. A Li-ion battery model has been added to the present analysis in order to compare the two technologies for this specific application.

Comparisons between technologies are widespread and often focus on the cost of these systems [9]-[12], though few actually perform a life cycle cost analysis [13], [14]. However, such an analysis proves to be critical, especially for stationary applications; to the best of our knowledge, no previous work has taken advanced aging models into account.

\section{MODELS AND HYPOTHESES}

\section{A. Rule-based Energy Management}

The complete system with all its power flows is illustrated in Figure 1.

The effects of losses on the dynamic behavior of the system are neglected because the dynamic behavior does not change significantly by not considering them. But, losses are not completely neglected; they are indeed part of the operating cost. With this assumption, the ESS is considered as a pure integrator. This assumption is often used for this type of problems, and can be summarized by the following equations:

$$
\begin{aligned}
\frac{d E_{\text {Sto }}}{d t} & =P_{\text {Sto }}(t) \\
P_{\text {Sto }}(t) & =P_{\text {Prod }}(t)-P_{\text {Grid }}(t)
\end{aligned}
$$

with $E_{S t o}$ the stored energy in the ESS, $P_{S t o}$ the power in the ESS, $P_{\text {Prod }}$ the power produced by the DWEC, and $P_{\text {Grid }}$ the power injected into the grid.

The energy management steps discussed herein are part of a rule-based control strategy with adjustment parameters that allows for optimizing these parameters (hence, optimizing process management) based on both the constraints and costs. The rule is that the stored power linearly depends both on the power produced and on the state of energy of the ESS. This type of law is inspired by fuzzy logic management [15]-[17]:

$$
P_{\text {Sto }}(t)=\alpha\left(P_{\text {Prod }}(t)-P_{\text {Min }}\right)-\frac{E_{\text {Sto }}(t)-E_{\text {Min }}}{\tau}
$$

Three adjustment parameters are found in this management law, i.e.: $E_{M i n}, \tau$ and $\alpha$, which respectively denote the minimum stored energy, the storage time constant, and a ratio (bounded between 0 and 1) that is proportional to the share of smoothed power within the power injected into the grid. $P_{\text {Min }}$ corresponds to the minimum instantaneous power (here $0 \mathrm{MW}$ ). This management rule is illustrated in Figure 3. For each sizing, the management parameters are chosen so as to minimize the speed of aging.

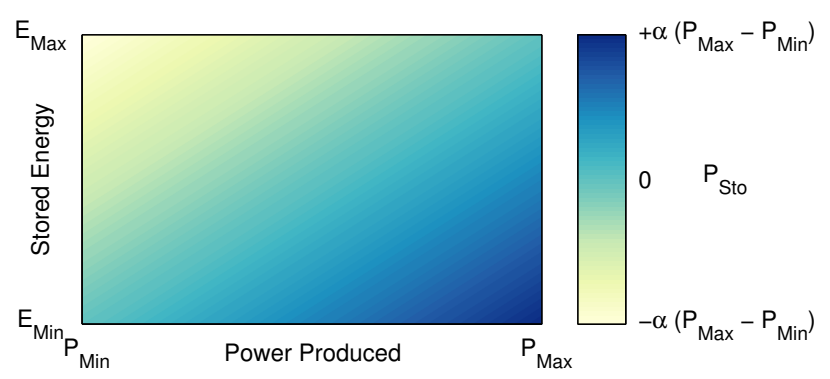

Fig. 3. Rule-based management strategy: stored power vs. the power produced by the Wave Energy Converter and the ESS State of Energy ( $\alpha$ is a parameter bounded between 0 and 1 )

The Energy Storage System is necessary to satisfy the flicker constraint for some sea-states. The maximum allowed long-term flicker severity value $P_{l t}$ for a wave farm is 0.25 , according to French rules for a MV grid (distribution mediumvoltage grid between $1 \mathrm{kV}$ and $50 \mathrm{kV}$, typically $20 \mathrm{kV}$ ).

The total long-term flicker severity value $P_{l t}$ for a farm with $N_{i}$ converters and the same individual long-term severity $P_{l t i}$ is assumed to equal: $P_{l t}=\sqrt{N_{i}} \times P_{l t i}$. The studied situation is a farm of 20 productive units; then, the limit for each unit would be: $0.25 / \sqrt{20}=0.056$. This constraint will be used to size the individual Energy Storage System (ESS), which is controlled individually.

Let's also assume that the grid has a short-circuit apparent power of 50 MVA and a grid impedance angle of $60^{\circ}$, both of which are values for a weak medium-voltage grid, typical from some near-shore or island grid. In order to partially compensate voltage fluctuation, the grid reactive power production is set to: $Q_{\text {Grid }}=-0.2 P_{\text {Grid }}$, the maximum authorized value.

An example of two management parameters that respect flicker constraint are in Fig. 4. We notice that the ESS is used more in power when $\alpha$ is big and more in energy when $\tau$ is big.

\section{B. Supercapacitors and Li-ion batteries electrical and thermal model}

For both technologies, a reference element is used: a Maxwell cell with a 3000 Farads capacitance and a 2.7 volt rated voltage [18] for the supercapacitors and an Altairnano battery (nanostructured lithium-titanate for the negative electrode and lithium-manganese oxide for the positive electrode) with a 60 Ampere-hour capacity and a 24 volt rated voltage [19] for Li-ion batteries. 

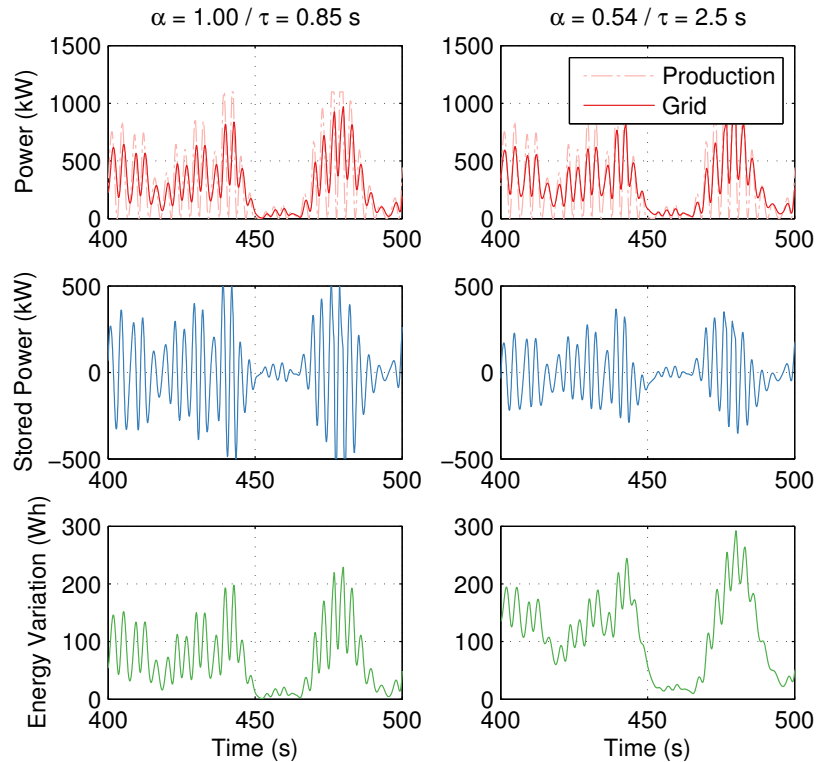

Fig. 4. Smoothing of Wave Energy Converter power production with two parameter pairs $(\alpha, \tau)$ that satisfy the flicker constraint

The electrical model chosen to represent a supercapacitor is the series connection of a capacitance $C(3000 \mathrm{~F})$ and an Equivalent Series Resistance $\operatorname{ESR}(0.29 \mathrm{~m} \Omega)$. We model the Li-ion battery by a voltage source $E(24 \mathrm{~V})$ and an internal resistance $E S R(3.9 \mathrm{~m} \Omega)$ in series. Both model are oversimplified, unless the State-of-Energy of the ESS stay relatively unchanged. We will make that hypothesis and try to confirm it with the results.

The series and parallel connections of these elements allow adjusting the rated voltage and total size of the ESS. All cells are assumed to be identical and to endure the same conditions. We can notice that balancing circuits are typically used to compensate voltage deviation between the cells, and thus help to make this assumption.

The self-heating effect is very important because the degradation rate accelerates exponentially with respect to temperature, as we will see later. The thermal time constant of the cells are considered to be high enough relative to the waves period (typically ten seconds) so as to neglect case temperature variations. In order to determine the case temperature of the elements, we thus introduce a simple static thermal model:

$$
\theta_{c}=\theta_{a}+R_{t h c a} \overline{E S R \times I(t)^{2}}
$$

where $\theta_{c}$ and $\theta_{a}$ are the case and the ambient temperatures (the latter is assumed to be constant and equal to $25^{\circ} \mathrm{C}$ ), $R_{\text {thca }}$ the thermal case-ambient resistance of the element, and $I$ the current flowing through the component. The operator $\bar{x}$ represents the average of a quantity over a cycle duration. Thus, during a cycle, the case temperature $\theta_{c}$ is considered as a constant. The thermal resistance $R_{t h c a}$ is $3.2 \mathrm{~K} / \mathrm{W}$ for supercapacitors and $0.28 \mathrm{~K} / \mathrm{W}$ for batteries (hypothesis: heat transfer coefficient is equal to $\left.10 \mathrm{~W} /\left(\mathrm{m}^{2} \mathrm{~K}\right)\right)$.

\section{Supercapacitors and batteries aging models}

A state variable $S o A$ serves to quantify the State-of-Aging for both aging models; its use is similar to the State-of-Health $\mathrm{SoH}$ parameter found in some battery models $(S o A=1-$ $S o H)$. The value is initially 0 and reaches 1 at the end of the device lifetime.

The supercapacitor aging model has been fully described in [4]. Aging variation depends on: the case temperature $\theta_{c}$, voltage across the cell $V$, and the root mean square current though the cell $I_{R M S}$ :

$$
\begin{aligned}
\delta S o A=\frac{1}{T_{\text {life }}^{r e f}} \times \exp \left(\frac{\theta_{c}-\theta_{c}^{r e f}}{\theta_{0}}\right) & \\
\times & {\left[\exp \left(\frac{V-V^{r e f}}{V_{0}}\right)+K\right] } \\
\times & \exp \left(k_{R M S} \frac{I_{R M S}}{C}\right) \times \delta t
\end{aligned}
$$

where $T_{\text {life }}^{r e f}, \theta_{0}, \theta_{c}^{r e f}, V_{0}, V^{r e f}, K$ and $k_{R M S}$ are aging parameters described in [4] and given in Table I. $\tau_{\text {filter }} R M S$ corresponds to the time constant used to compute the RMScurrent $I_{R M S}$. The temporal resolution used here to compute the average aging speed is $0.1 \mathrm{~s}$. $\delta t$ is the duration of the seastate considered.

TABLE I

PARAMETERS OF THE SUPERCAPACITORS AGING MODEL

\begin{tabular}{c|c}
$\theta_{0}$ & $11 \mathrm{~K}$ \\
\hline$V_{0}$ & $130 \mathrm{mV}$ \\
\hline$K$ & $29 \times 10^{-3}$ \\
\hline$T_{\text {life }}^{\text {ref }}$ & $1470 \mathrm{~h}$ \\
\hline$V^{\text {ref }}$ & $2.7 \mathrm{~V}$ \\
\hline$\theta^{\text {ref }}$ & $65^{\circ} \mathrm{C}$ \\
\hline$k_{R M S}$ & $68 \mathrm{~s} . \mathrm{V}^{-1}$ \\
\hline$\tau_{\text {filter RMS }}$ & $45 \mathrm{~s}$
\end{tabular}

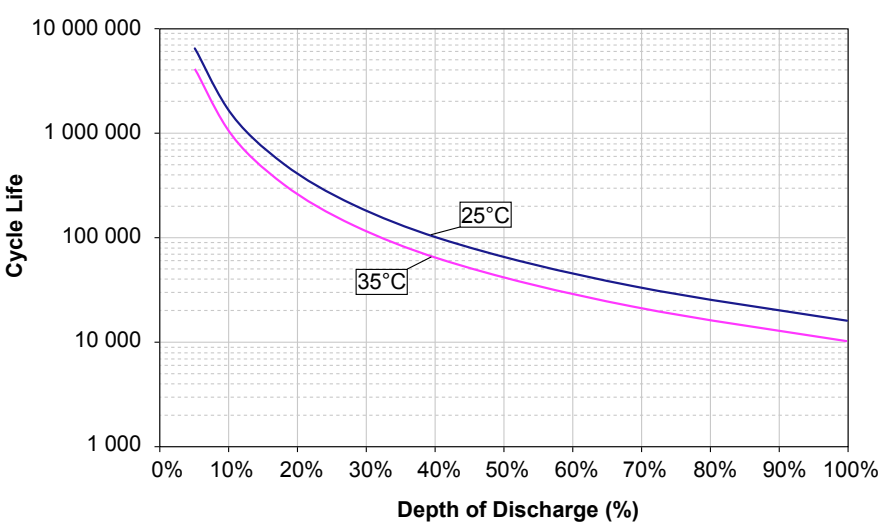

Fig. 5. Cycling model of Altairnano Lithium nanostructured lithium-titanate batteries [20]

The Li-ion battery aging model is a cycling model based on manufacturers data (see Fig. 5) that take into account both 
cycling and calendar aging.

$$
\begin{aligned}
\delta S o A= & {\left[\sum_{i=1}^{N} \frac{D o D_{i}^{2}}{2 N_{\text {cycles }}^{\text {ref }}}+\frac{\delta t}{T_{\text {calendar }}^{\text {ref }}}\right] } \\
& \times \exp \left(\frac{\theta_{c}-\theta_{c}^{\text {ref }}}{\theta_{0}}\right)
\end{aligned}
$$

where $N$ is the total number of half-cycles during a seastate with a duration of $\delta t, i$ is the index of the half-cycle (a charge or a discharge) and $D o D_{i}$ is the Depth of Discharge or Charge during the half-cycle $i$, as a ratio of the energy fluctuation over the rated energy. The parameters $N_{\text {cycles }}^{r e f}, \theta_{0}$, $\theta_{c}^{r e f}$ and $T_{\text {calendar }}^{r e f}$ are given in Table II. A rainflow-counting algorithm is used to determine all half-cycles. It transforms time series into various cycles in order to apply cycling aging models in the case of complex loading [21]. This algorithm has been described in detail in the relevant standard [22], and a MATLAB implementation is given in [23].

TABLE II

PARAMETERS OF THE LI-ION BATTERY AGING MODEL

\begin{tabular}{c|c}
$N_{\text {cycles }}^{\text {ref }}$ & 16000 \\
\hline$T_{\text {calendar }}^{\text {ref }}$ & 25 years \\
\hline$\theta_{c}^{\text {ref }}$ & $25^{\circ} \mathrm{C}$ \\
\hline$\theta_{0}$ & $22 \mathrm{~K}$
\end{tabular}

\section{Sizing Minimizing Life Cycle Cost}

\section{A. Life Cycle Cost Analysis}

The goal of this model is to determine the sizing that minimizes total lifetime cost $C_{\text {life }}$; this cost takes into account the price of losses using a feed-in tariff set at $c_{\text {Feed-in }}=$ $0.15 € / \mathrm{kWh}$, with the initial investment costing $c_{\text {Energy }}=$ $15 \mathrm{k} € / \mathrm{kWh}$ for the supercapacitors and $c_{\text {Energy }}=300 € / \mathrm{kWh}$ for power Li-ion batteries (Lithium Iron Phosphate price with some suppliers). The replacement cost considers just the price of the new storage system. So, this model does not take into account either the intervention cost or production losses during failure, both of which can be considerable in an offshore system.

$$
\begin{aligned}
C_{\text {life }}= & c_{\text {Energy }} E_{\text {Rated }} \\
& +c_{\text {Energy }} N_{\text {replace }} E_{\text {Rated }} \\
& +c_{\text {Feed-in }}<P_{\text {loss }}>\Delta t
\end{aligned}
$$

where $\Delta t$ is the lifetime of the DWEC system, taken at 20 years and $N_{\text {replace }}$ is the number of replacements and is an integer, its value comes from the relation:

$$
N_{\text {replace }}=\left\lfloor\int_{0}^{\Delta t} \frac{\mathrm{d} S o A}{\mathrm{~d} t} \mathrm{~d} t\right\rfloor
$$

where $\lfloor x\rfloor$ is the floor function, that is the largest integer not greater than $\mathrm{x}$ and $\mathrm{d} S o A / \mathrm{d} t$ is the aging speed averaged over a sea-state.
Results are shown in Figure 6. The investment cost is proportional to the capacity, the losses are inversely proportional to the capacity and the replacement are many with small size due to large cycles and high self-heating. The cost are similar despite the major differences in capacity between the two technologies because the application demands a lot of power compared to the need of energy.

The life cycle cost discontinuity comes from the number of replacements, which is an integer. We can see that there is a big problem of robustness because a little change in capacity can have a great impact on life cycle cost.
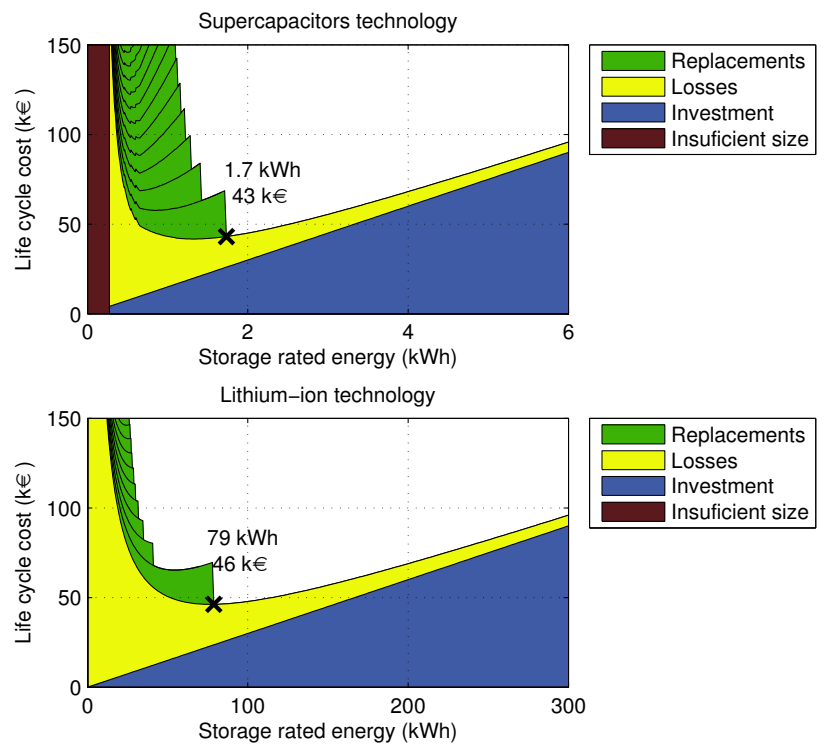

Fig. 6. Life cycle cost as a function of energy capacity for an ambient temperature of $25^{\circ} \mathrm{C}$

\section{B. Considering aging model uncertainty}

The aging models are not sufficiently accurate to make sure prediction about replacement. That is why we want to take into account the uncertainty concerning the aging model and hypotheses that have impact on aging, such as a constant ambient temperature. It is usual during a model fitting to have experiments that differ from model within a factor 2 , and it is not rare to find a factor 3 .

That is why we will now consider that the number of replacement is a stochastic variable $N_{\text {replace }}^{\text {stoch. }}$ with a multiplicative factor $e^{x}$ that follows a normal distribution:

$$
N_{\text {replace }}^{\text {stoch. }}(x)=\left\lfloor\int_{0}^{\Delta t} e^{x} \frac{\mathrm{d} S o A}{\mathrm{~d} t} \mathrm{~d} t\right\rfloor
$$

with $\lfloor x\rfloor$, the floor function, $x$, a stochastic variable that follow a normal distribution $\phi(x)$ whose mean value is 0 (there is the same chance to underestimate or to overestimate the lifetime) and whose standard deviation is $\sigma=\ln (2)$, corresponding to a typical error factor of 2 (the lifetime prediction is two time shorter or longer than the real lifetime). 
And we can compare this variable with the median value of the lifetime for the Energy Storage System M $\left(T_{\text {life }}\right.$ ESS $)$ that corresponds to the inverse of the average aging speed, i.e.:

$$
\mathbf{M}\left(T_{\text {life } E S S}\right)=\left(\frac{1}{\Delta t} \int_{0}^{\Delta t} \frac{\mathrm{d} S o A}{\mathrm{~d} t} \mathrm{~d} t\right)^{-1}
$$

Fig. 7 illustrated this relation. This figure shows the number of replacement as a function of the median value of the lifetime $\mathbf{M}\left(T_{\text {life ESS }}\right)$, calculated using (5) and (6). The usage time for the complete DWEC is supposed to be 20 years. The different areas represent different probabilities to have a number of replacement during this period of time. This is close to reliability or decision risk approaches. For a lifetime prediction of 20, 40 and 60 years, we can see the probability to have a given number of replacements $(0,1,2$ or 3$)$ during the considered lifetime. We can notice that Fig. 7 does not depend on the aging model or even the problem, but only on the distribution choose to represent the uncertainty.

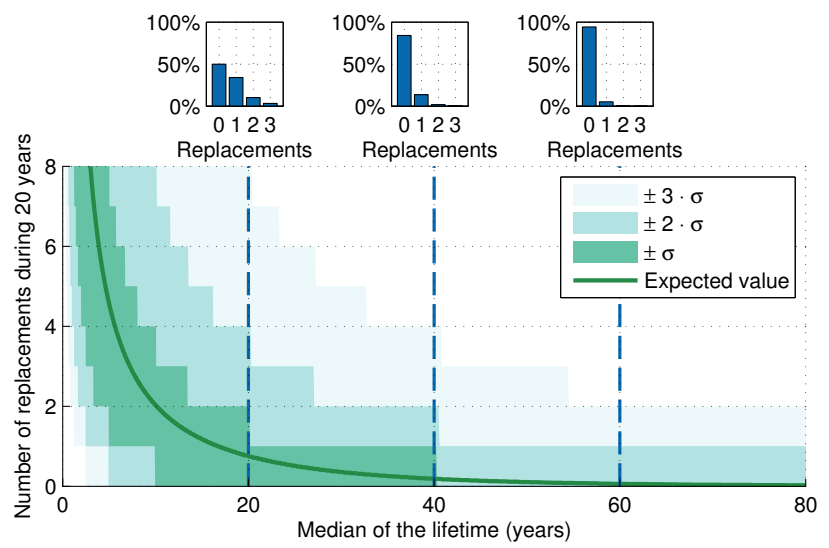

Fig. 7. Stochastic aging model: replacement as a function of the median value of the lifetime (calculated using (5) and (6)). For a median value of 20 , 40 and 60 years, the probabilities to have $0,1,2$ or 3 replacements during a usage time of 20 years are shown.

\section{Results}

The expected value of the cost as a function of rated energy for both technolgies is shown in Fig. 8. For this figure, we change the replacement cost with its expected value :

$$
\begin{aligned}
\mathbf{E}\left(C_{\text {life }}\right)= & c_{\text {Energy }} E_{\text {Rated }} \\
& +c_{\text {Energy }} \mathbf{E}\left(N_{\text {replace }}^{\text {stoch. }}\right) E_{\text {Rated }} \\
& +c_{\text {Feed-in }}\left\langle P_{\text {loss }}\right\rangle \Delta t
\end{aligned}
$$

We can notice that the supercapacitors solution is a trade-off between investment and replacements and the battery solution is more a trade-off between investment and losses.

Table III lists selected characteristics of two optimal solutions. While the rated energy and expected lifetime results differ by a wide margin, a similar price and weight is still found even though, in this case, the supercapacitor seems to be the cheaper solution.

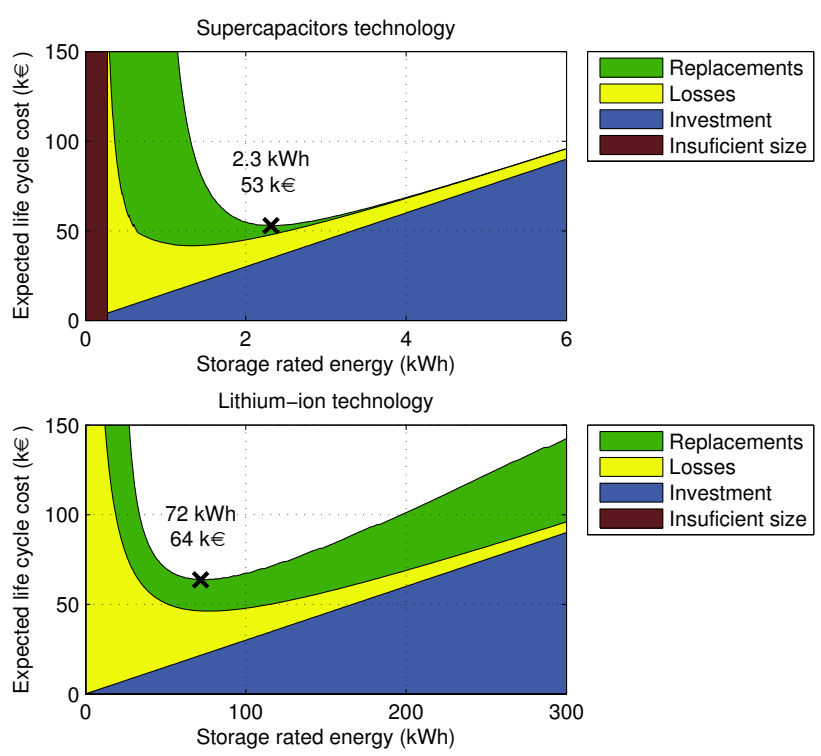

Fig. 8. Expected life cycle cost as a function of energy capacity with uncertain aging models for an ambient temperature of $25^{\circ} \mathrm{C}$

The energy used is around $0.25 \mathrm{kWh}$, that is very small compared to the energy capacity in both case. So the State-ofEnergy with both technologies is almost constant, so the simplified electrical models are partly justified (State-of-Charge dependency is not useful here).

TABLE III

COMPARISON OF THE TWO OPTIMUMS (AMBIANT TEMPERATURE: $25^{\circ} \mathrm{C}$ )

\begin{tabular}{c|c|c} 
& Supercapacitor & Li-ion battery \\
\hline$E_{\text {rated }}$ & $2.3 \mathrm{kWh}$ & $75 \mathrm{kWh}$ \\
\hline $\mathbf{E}\left(C_{\text {life }}\right)$ & $53 \mathrm{k} €$ & $64 \mathrm{k} €$ \\
\hline$P_{\text {rated }}$ & $1.7 \mathrm{MW}$ & $0.75 \mathrm{MW}$ \\
\hline Weight & $1000 \mathrm{~kg}$ & $1400 \mathrm{~kg}$ \\
\hline Volume & $2.2 \mathrm{~m}^{3}$ & $0.70 \mathrm{~m}^{3}$ \\
\hline Round trip efficiency & $98 \%$ & $96 \%$ \\
\hline Expected lifetime $\mathbf{M}\left(T_{\text {life }} E S S\right)$ & 44 years & 20 years \\
\hline Probability $\left(N_{\text {replace }}=0\right)$ & $87 \%$ & $49 \%$ \\
\hline Probability $\left(N_{\text {replace }}=1\right)$ & $11 \%$ & $35 \%$ \\
\hline Probability $\left(N_{\text {replace }}=2\right)$ & $1.3 \%$ & $11 \%$
\end{tabular}

Because the aging is important for the cost, the life cycle cost has an important dependency on ambient temperature (see Fig. 9). The optimum for battery technology does not change a lot with the ambient temperature, because it is mainly a trade-off between losses and investment that does not depend on aging. The supercapacitor optimum size is bigger when temperature is bigger because it is a trade-off between investment and replacements, that depends a lot on aging. For the same reason, the optimum for supercapacitor does not depend a lot on storage price while the optimum for Li-ion battery changes with price. 

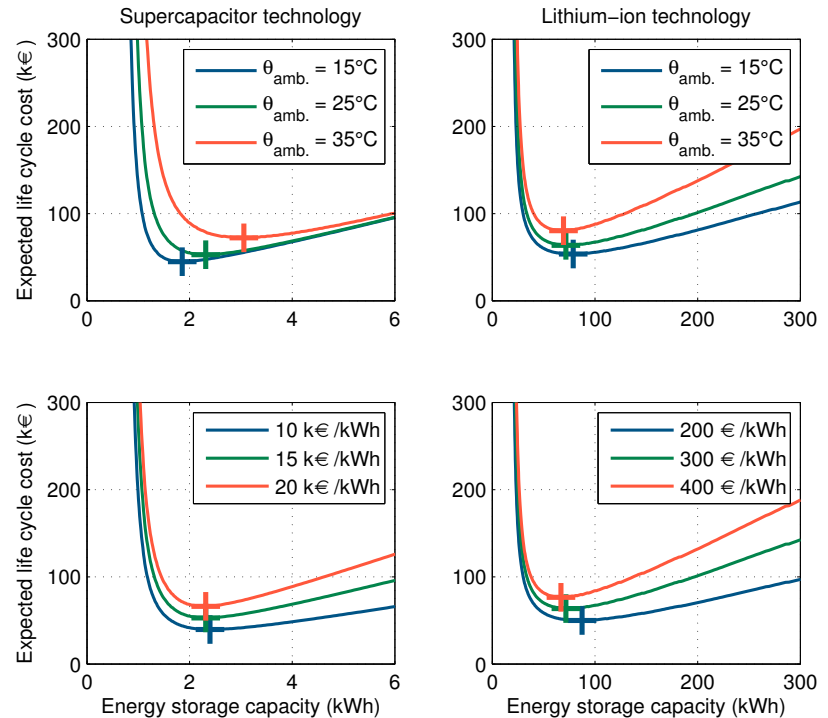

Fig. 9. Ambient temperature and energy cost dependency of the sizing and the life cycle cost

\section{CONCLUSION}

The goal of this study is to determine which technology has the lowest life cycle cost between supercapacitors and Liion batteries in a specific case, that is smoothing Direct Wave Energy Converter with a flicker constraint.

For this purpose, we use electrical, thermal, aging and cost models. The life cycle cost analysis proposed here considers the investment, the replacements and the losses.

The first optimum seems to suffer from a lack of robustness, so we decide to take into account the uncertainty of aging models with an error factor that follows a normal distribution.

Supercapacitors seems to be cheaper for this application, but power $\mathrm{Li}$-ion batteries are not excessively more expensive and results may change if battery prices fall faster than those of supercapacitor.

The purpose of the sizing is to minimize life cycle costs. The final life cycle cost of around $53 \mathrm{k} €$ seems to be admissible, representing an impact on energy costs around $2.4 €$ per MWh produced.

To further decrease this cost, several solutions can be studied such as an improved energy management [24].

This study is only part of the design of a complete electric conversion chain that takes lifetime into account [25] [26]. In the case of DWEC, other more efficient control strategies to convert wave energy are available [27], though these would also be more stringent in terms of power fluctuation and hence in terms of flicker and fatigue cycling. The influence of such control strategies for energy conversion should be considered in future research on this topic.

\section{REFERENCES}

[1] B. Barahona and P. Sø rensen, "Validation of the standard method for assessing flicker from wind turbines," Energy Conversion, IEEE Transactions on, vol. 26, no. 1, pp. 373-378, 2011.
[2] J. Aubry, "Optimisation du dimensionnement d'une chaîne de conversion électrique directe incluant un système de lissage de production par supercondensateurs. Application au houlogénérateur SEAREV." thèse de doctorat, thèse de doctorat de l'Ecole Normale Supérieure de Cachan, 2011. [Online]. Available: http://tel.archives-ouvertes.fr/tel-00662488

[3] A. Blavette, D. L. O'Sullivan, T. W. Lewis, and M. G. Egan, "Dimensioning the equipment of a wave farm: Energy storage and cables," in Ecological Vehicles and Renewable Energies (EVER), Monte-Carlo, Monaco, Mar. 2013, pp. 1-9.

[4] T. Kovaltchouk, B. Multon, H. Ben Ahmed, J. Aubry, and P. Venet, "Enhanced aging model for supercapacitors taking into account power cycling: Application to the sizing of an Energy Storage System in a Direct Wave Energy Converter," in Ecological Vehicles and Renewable Energies (EVER), Monte-Carlo, Monaco, Mar. 2014, pp. 1-10.

[5] A. Babarit and A. H. Clément, "Optimal latching control of a wave energy device in regular and irregular waves," Applied Ocean Research, vol. 28, no. 2, pp. 77-91, Apr. 2006.

[6] J. Aubry, P. Bydlowski, B. Multon, H. Ben Ahmed, and B. Borgarino, "Energy Storage System Sizing for Smoothing Power Generation of Direct Wave Energy Converters," in 3rd International Conference on Ocean Energy, Bilbao, Oct. 2010, pp. 1-7. [Online]. Available: http://hal.archives-ouvertes.fr/hal-00526435/

[7] P. Haessig, B. Multon, H. Ben Ahmed, S. Lascaud, and L. Jamy, "Aging-aware NaS battery model in a stochastic wind-storage simulation framework," in PowerTech, IEEE, Grenoble, 2013.

[8] R. Le Goff Latimier, T. Kovaltchouk, H. Ben Ahmed, and B. Multon, "Preliminary Sizing of a Collaborative System : Photovoltaic Power Plant and Electric Vehicle Fleet," in Ecological Vehicles and Renewable Energies (EVER), Monaco, 2014.

[9] V. Musolino and E. Tironi, "A comparison of supercapacitor and highpower lithium batteries," in Electrical Systems for Aircraft, Railway and Ship Propulsion (ESARS), 2010, 2010, pp. 1-6.

[10] R. T. Doucette and M. D. McCulloch, "A comparison of high-speed flywheels, batteries, and ultracapacitors on the bases of cost and fuel economy as the energy storage system in a fuel cell based hybrid electric vehicle," Journal of Power Sources, vol. 196, no. 3, pp. 1163-1170, Feb. 2011.

[11] International Electrotechnical Commission (IEC), "Electrical Energy Storage White paper," Tech. Rep. December, 2011.

[12] Z. Zhou, M. Benbouzid, J. F. Charpentier, F. Scuiller, and T. Tang, "A review of energy storage technologies for marine current energy systems," Renewable and Sustainable Energy Reviews, vol. 18, pp. 390400, Feb. 2013

[13] S. Schoenung and W. Hassenzahl, "Long-vs. Short-Term Energy Storage Technologies Analysis. A Life-Cycle Cost Study. A Study for the DOE Energy Storage Systems Program," Sandia National Laboratories, Tech. Rep., 2003.

[14] S. Upadhyay and M. Sharma, "A review on configurations, control and sizing methodologies of hybrid energy systems," Renewable and Sustainable Energy Reviews, vol. 38, pp. 47-63, Oct. 2014.

[15] S. Caux, J. Lachaize, M. Fadel, P. Shott, and L. Nicod, "Modelling and control of a Fuel Cell System and Storage Elements in transport applications," Journal of Process Control, vol. 15, no. 4, pp. 481-491, Jun. 2005.

[16] S. M. Muyeen, R. Takahashi, T. Murata, and J. Tamura, "Integration of an Energy Capacitor System With a Variable-Speed Wind Generator," IEEE Transactions on Energy Conversion, vol. 24, no. 3, pp. 740-749, Sep. 2009.

[17] G. Suvire and P. Mercado, "Active power control of a flywheel energy storage system for wind energy applications," IET Renewable Power Generation, vol. 6, no. 1, pp. 9-16, 2012.

[18] Maxwell Technologies, "Datasheet K2 Series Ultracapacitors," pp. 1-4, 2007.

[19] Altairnano, "Datasheet $24 \mathrm{~V} 60$ Ah Battery Module, nano LithiumTitanate battery module," 2011.

[20] B. Misback and Altairnano, "Large Format Li4Ti5O12 Lithium-Ion Batteries Performance and Applications," in Li Mobile Power. Boston: Altairnano, 2010, pp. 1-13.

[21] S. Downing and D. Socie, "Simple rainflow counting algorithms," International Journal of Fatigue, no. January, pp. 31-40, 1982.

[22] American Society for Testing and Materials, "E-1049 85 (Reapproved 2011). Standard practices for cycle counting in fatigue analysis," Tech. Rep., 1985. 
[23] A. Nieslony, "Determination of fragments of multiaxial service loading strongly influencing the fatigue of machine components," Mechanical Systems and Signal Processing, vol. 23, no. 8, pp. 2712-2721, Nov. 2009.

[24] P. Haessig, T. Kovaltchouk, B. Multon, H. Ben Ahmed, and S. Lascaud, "Computing an Optimal Control Policy for an Energy Storage," in EuroScyPy, Brussels, Belgium, Aug. 2013, pp. 1-8.

[25] J. Aubry, H. Ben Ahmed, and B. Multon, "Sizing Optimization Methodology of a Surface Permanent Magnet Machine-Converter System over a Torque-Speed Operating Profile : Application to a Wave Energy Converter," Industrial Electronics, IEEE Transactions on, vol. 59, no. 5 , pp. 2116,2125, 2012.

[26] T. Kovaltchouk, J. Aubry, B. Multon, and H. Ben Ahmed, "Influence of IGBT current rating on the thermal cycling lifetime of a power electronic active rectifier in a direct wave energy converter," in Power Electronics and Applications (EPE), Lille, 2013, pp. 1-10.

[27] T. Kovaltchouk, B. Multon, H. Ben Ahmed, F. Rongère, A. Glumineau, and J. Aubry, "Influence of control strategy on the global efficiency of a Direct Wave Energy Converter with electric Power Take-Off," in Ecological Vehicles and Renewable Energies (EVER), Monte-Carlo, Monaco, Mar. 2013, pp. 1-10. 